\title{
Comparison of hepatic and renal function between inhalation anesthesia with sevoflurane and remifentanil and total intravenous anesthesia with propofol and remifentanil for thyroidectomy
}

\author{
Ji Wook Kim, Joo Duck Kim, Soo Bong Yu, and Sie Jeong Ryu \\ Department of Anesthesiology and Pain Medicine, College of Medicine, Kosin University, Busan, Korea
}

Background: Inhalation anesthetics are an important factor for postoperative hepatic and renal dysfunction. In this regard, TIVA can reduce the risk of hepatic and renal dysfunction inherited to inhalation anesthetics. The present study was conducted to determine whether hepatic and renal functions differ after anesthesia with sevoflurane and propofol.

Methods: Two hundred patients, ASA physical status class I, II, scheduled for an elective thyroidectomy were randomly divided into two groups. Anesthesia was maintained with sevoflurane $1-2 \%$ and remifentanil in the sevoflurane group (Group S) and propofol 2-5 ug/ml and remifentanil $2-5 \mathrm{ng} / \mathrm{ml}$ at the effect site, using a target controlled infusion (TCI) pump in the TIVA group (Group T) to maintain BIS of 40-60. To evaluate the hepatic and renal function, aspartate aminotransferase (AST), alanine aminotransferase (ALT), blood urea nitrogen (BUN) and creatinine were tested at preoperation (baseline), postoperative 1 day and 3 days.

Results: AST was increased at postoperative 1 day and 3 days, compared with that of the preoperation in Group S, and postoperative 1 day in Group T, but the values were within its normal limit. ALT was not changed after anesthesia in both groups. BUN was increased at postoperative 1 day, compared with that of the preoperation in Group S, but the value was within its normal limit. Creatinine was not changed after anesthesia in both groups.

Conclusions: The changes of hepatic and renal function after inhalation anesthesia with sevoflurane and TIVA with propofol and remifentanil for thyroidectomy were clinically insignificant, and there was no difference between the two methods. (Korean J Anesthesiol 2013; 64: 112-116)

Key Words: Alanine aminotransferase, Aspartate aminotransferase, Blood Urea Nitrogen (BUN), Creatinine, Inhalation anesthesia, Total intravenous anesthesia.

Received: March 9, 2012. Revised: 1st, May 4, 2012; 2nd, June 15, 2012. Accepted: June 20, 2012.

Corresponding author: Sie Jeong Ryu, M.D., Department of Anesthesiology and Pain Medicine, College of Medicine, Kosin University, 34, Amnam-dong, Seo-gu, Busan 602-702, Korea. Tel: 82-51-990-6283, Fax: 82-51-254-2504, E-mail: siejeong@ns.kosinmed.or.kr (c) This is an open-access article distributed under the terms of the Creative Commons Attribution Non-Commercial License (http:// creativecommons.org/licenses/by-nc/3.0/), which permits unrestricted non-commercial use, distribution, and reproduction in any medium, provided the original work is properly cited. 


\section{Introduction}

Postoperative liver and kidney function are affected by anesthetics and their metabolites, as well as by sympathetic stimulation, decrease in blood perfusion, underlying diseases, viral hepatitis, sepsis, drug reactions, side effects and damage from surgeries [1,2]. Halothane, which is a typical inhalational anesthetic, is known for its liver and kidney toxicity. A new inhalational anesthetic, sevoflurane, has recently been developed and is now frequently used. Total intravenous anesthesia (TIVA) with propofol is commonly used as an ideal balanced anesthesia. Because TIVA is known to have early emergence from general anesthesia and can reduce postoperative nausea and vomiting, it is becoming favored as a general anesthetic [3]. TIVA with propofol is expected to have a lower risk of direct damage from anesthetic metabolites, and shows hemodynamic stability during anesthesia [4]. However, few prospective studies have been performed on the effects of inhalational anesthetics and TIVA on liver and kidney function. In addition, previous studies comparing sevoflurane and propofol have variable results $[5,6]$ with small sample sizes (20-40), and limited ability to analyze the effects of anesthetics, because they included patients who underwent surgeries that could directly affect liver and renal function.

In the present study, we examined differences in postoperative liver and kidney function when using inhalation anesthesia with sevoflurane or TIVA with propofol. The present study was performed in a sample of patients who underwent thyroidectomy, a surgery that has no direct effect on the liver and kidney.

\section{Materials and Methods}

The study was done using a sample of 200 American Society of Anesthesiologists physical status I and II patients who were scheduled for thyroidectomy, between the ages of $20-$ 65 years. The Institutional Review Board approved this study. The purpose and methodology of the study were explained to patients before obtaining consent. Patients with liver or kidney

Table 1. Demographic Data

\begin{tabular}{lcc}
\hline & $\begin{array}{c}\text { Group S } \\
(\mathrm{n}=100)\end{array}$ & $\begin{array}{c}\text { Group T } \\
(\mathrm{n}=100)\end{array}$ \\
\hline Sex (M/F) & $11 / 89$ & $22 / 78$ \\
Age (yr) & $44.6 \pm 10.5$ & $44.5 \pm 10.2$ \\
Height (cm) & $161.0 \pm 6.9$ & $161.7 \pm 7.9$ \\
Weight (kg) & $61.3 \pm 10.7$ & $62.4 \pm 11.4$ \\
\hline
\end{tabular}

$\overline{\text { Values are mean } \pm \text { SD. Group S: inhalation anesthesia with sevo- }}$ flurane, Group T: total intravenous anesthesia with propofol and remifentanil. There were no difference between two groups. abnormalities, hypertension or diabetes, surgical history in the past month and intraoperative hypotension, or blood transfusion were excluded from the study. The patients were randomly assigned to two groups of 100 patients each. The two groups were Group S, which received sevoflurane and remifentanil, and Group T, which received TIVA with propofol and remifentanil with a target controlled infusion pump (TCI pump). There were no differences in sex, age, height, and weight between the two groups (Table 1).

All patients were premedicated with $0.05 \mathrm{mg} / \mathrm{kg}$ midazolam (Dormicum ${ }^{\circledR}$, Roche, Switzerland) and $50 \mathrm{mg}$ ranitidine (Urantac $^{\mathrm{TM}}$, Whanin, Korea) for $30 \mathrm{~min}$ before undergoing anesthesia. Venous access was secured with an $18 \mathrm{G}$ needle, and lactated Ringer's solution was infused at $2 \mathrm{ml} / \mathrm{kg} / \mathrm{hr}$. For anesthesia induction, spontaneous breathing with $100 \%$ oxygen was performed for $2 \mathrm{~min}$ for denitrogenation. Then, $0.2 \mathrm{mg}$ glycopyrrolate (Mobinul ${ }^{\mathrm{TM}}$, Myungmoon, Korea) was administered. To induce loss of consciousness, Group $\mathrm{S}$ received $0.05 \mathrm{mg} / \mathrm{kg}$ midazolam and $1 \mathrm{mg} / \mathrm{kg}$ propofol (Provive ${ }^{\mathrm{TM}}$, Claris, India), and remifentanil was administered using an infusion pump at a rate of $10 \mathrm{ug} / \mathrm{kg} / \mathrm{hr}$. In Group T, a TCI pump (Ochestra Base Premea, France) was set for propofol at $4 \mathrm{ug} / \mathrm{ml}$ and remifentanil (Ultiva ${ }^{\mathrm{TM}}, \mathrm{GSK}$, Italy) at $4 \mathrm{ng} / \mathrm{ml}$ as the effect-site concentration. For tracheal intubation, $0.9 \mathrm{mg} / \mathrm{kg}$ rocuronium (Esmeron ${ }^{\circledR}$, Organon, Netherlands) was administered $90 \mathrm{sec}$ after the patient was intubated. For anesthesia maintenance, controlled ventilation was conducted to maintain the $\mathrm{ETCO}_{2}$ at $30-35 \mathrm{mmHg}$ with $\mathrm{O}_{2}$ : air $=1.5 \mathrm{~L} / \mathrm{min}: 2.5 \mathrm{~L} / \mathrm{min}$, the respiratory rate at $10-12$ breaths $/ \mathrm{min}$, and the tidal volume at $7-10 \mathrm{ml} / \mathrm{kg}$. Group S received 1-2\% sevoflurane with continuous infusion of remifentanil (2-15 ug/kg/hr) using an infusion pump. Group T used the TCI pump and the effect-site concentration of propofol and remifentanil was adjusted to SBP $\pm 20 \%$ of baseline. The bispectral index (BIS, Vista ${ }^{\mathrm{TM}}$, USA) was maintained at 40-60. For muscle relaxation, vecuronium (Vecron ${ }^{\mathrm{TM}}$, Myungmoon, Korea) was used intermittently. For fluid administration during surgery, lactated Ringer's solution was administered at $4-6 \mathrm{ml} / \mathrm{kg} / \mathrm{hr}$, depending on urine output and blood loss. Along with BIS, blood pressure, EKG, $\mathrm{SpO}_{2}, \mathrm{ETCO}_{2}$, and body temperature were monitored during surgery. To evaluate liver and kidney function, aspartate aminotransferase (AST), alanine aminotransferase (ALT), blood urea nitrogen (BUN), and creatinine were checked preoperatively (baseline), and on postoperative days 1 and 3. Comparisons of the two groups based on factors that affect kidney and liver function during surgery were performed by measuring the perioperative fluid volume, urine output, and anesthesia time. The two groups were equally given $1 \mathrm{~g}$ amoxicillin (Augmentin ${ }^{\mathrm{TM}}$, Ilsung, Korea) twice a day for five days and $90 \mathrm{mg}$ diclofenac (Neufenac ${ }^{\mathrm{TM}}$, Ajoo, Korea) twice a day for one day. 
The data are presented as the mean \pm standard deviation, and statistical analysis was performed with PASW Statistics 18 (Predictive Analytics Software; SPSS Inc., Chicago, IL, USA). Comparisons between the patient characteristics, perioperative fluid administration amount, urine output, and anesthesia time were performed using unpaired t-tests. Comparisons between liver and kidney function within each group and between the two groups were done by repeated measured ANOVA. P $<0.05$ was considered statistically significant.

\section{Results}

There were no differences between the two groups in type of thyroidectomy, perioperative fluid volume, urine output, amount of blood loss, anesthesia time, and amount of remifentanil used (Table 2).

The AST levels in Group S significantly increased on postoperative day $1(28.4 \pm 13.5, \mathrm{P}<0.001)$ and day $3(28.2 \pm$ $14.2, \mathrm{P}<0.001)$, compared to baseline $(20.9 \pm 4.4)$. The AST levels in Group $\mathrm{T}$ significantly increased on postoperative day $1(25.3 \pm 9.4, \mathrm{P}<0.001)$, compared to baseline $(21.9 \pm 5.9)$ (Table 3). Between the two groups, Group S had a significantly higher AST level than did Group T $(\mathrm{P}=0.048)$, but AST levels in both groups were within the normal range. The numbers of patients who had postoperative AST greater than $40 \mathrm{IU} / \mathrm{L}$ were 14 in Group S and 7 in Group T, but there were no significant differences between the two groups $(\mathrm{P}=0.083)$. There were no cases in which AST increased above $100 \mathrm{IU} / \mathrm{L}$.

There were no changes in ALT after anesthesia in either group, and there were no differences between the two groups (Table 3). The numbers of patients who had postoperative ALT greater than $40 \mathrm{IU} / \mathrm{L}$ were 4 in Group S and 4 in Group T.

Table 2. Comparison of Variables related to Operation between Two Groups

\begin{tabular}{lcc}
\hline & $\begin{array}{c}\text { Group S } \\
(\mathrm{n}=100)\end{array}$ & $\begin{array}{c}\text { Group T } \\
(\mathrm{n}=100)\end{array}$ \\
\hline Operation name & & \\
$\quad$ TT with CCND & 66 & 72 \\
Lobectomy with CCND & 29 & 22 \\
$\quad$ TT with mRND & 5 & 6 \\
Fluid input (ml) & $1,419.0 \pm 415.5$ & $1,391.0 \pm 517.5$ \\
Urine output (ml) & $733.4 \pm 448.4$ & $623.0 \pm 534.0$ \\
Anesthetic time (min) & $195.4 \pm 54.4$ & $185.8 \pm 63.5$ \\
Remifentanil use (mg) & $1.14 \pm 0.49$ & $1.22 \pm 0.46$ \\
\hline
\end{tabular}

Values are number of patients or mean \pm SD. Group S: inhalation anesthesia with sevoflurane, Group T: total intravenous anesthesia with propofol and remifentanil, TT with CCND: total thyroidectomy with central compartment neck dissection, Lobectomy with CCND: thyroid lobectomy with central compartment neck dissection, TT with mRND: total thyroidectomy with modified radical neck dissection.
The BUN levels in Group S increased significantly on postoperative day $1(14.7 \pm 4.2)(\mathrm{P}=0.008)$, compared to baseline $(13.2 \pm 3.7)$, but was in the normal range. The BUN levels in Group T did not change postoperatively and there were no differences between the two groups (Table 4). BUN levels outside of the normal range occurred in 1 patient in Group $S$ on postoperative day 1 and in 2 patients on postoperative day 3 . In Group T, there was 1 patient with BUN levels out of the normal range on postoperative day 3 . There were no changes in serum creatinine after anesthesia in either group, and there were no differences between the two groups (Table 4).

\section{Discussion}

Thyroidectomies are known to not cause direct surgical damage to the liver and kidney. They are also associated with low levels of postoperative pain. The surgical site is usually clean and there is little blood loss, and therefore antibiotic and analgesic use can be reduced. Therefore, the context of thyroidectomies are good for the study of the direct effects of anesthetics [7,8].

To assess liver function, albumin, gamma-glutamyl transpeptidase, prothrombin time, and cholesterol may be tested. AST and ALT levels are also often used as screening tests. AST is found not only in the liver, but also in the heart, kidney, and

Table 3. The Changes of Aspartate Aminotransferase (AST) and Alanine Aminotransferase (ALT)

\begin{tabular}{llllll}
\hline & \multicolumn{2}{c}{ AST (IU/L) } & & \multicolumn{2}{c}{ ALT (IU/L) } \\
\cline { 2 - 3 } \cline { 5 - 6 } & Group S* & Group T & & Group S & Group T \\
\hline Preoperative & $20.9 \pm 4.4$ & $21.9 \pm 5.9$ & & $20.1 \pm 7.1$ & $20.6 \pm 7.9$ \\
POD1 & $28.4 \pm 13.5^{\dagger}$ & $25.3 \pm 9.4^{\dagger}$ & & $18.8 \pm 14.2$ & $18.1 \pm 11.2$ \\
POD3 & $28.2 \pm 14.2^{\dagger}$ & $23.6 \pm 9.3$ & & $20.7 \pm 14.3$ & $20.0 \pm 10.7$ \\
\hline
\end{tabular}

Values are mean \pm SD. Group S: inhalation anesthesia with sevoflurane, Group T: total intravenous anesthesia with propofol and remifentanil. POD1: postoperative 1 day, POD3: postoperative 3 days. ${ }^{*} \mathrm{P}<0.05$ compared with Group $\mathrm{T}$ (measured by repeated measured ANOVA). ${ }^{\dagger} \mathrm{P}<0.01$ compared with preoperative value.

Table 4. The Changes of Blood Urea Nitrogen (BUN) and Serum Creatinine

\begin{tabular}{lccccc}
\hline & \multicolumn{2}{c}{ BUN $(\mathrm{mg} / \mathrm{dl})$} & & \multicolumn{2}{c}{ Creatinine $(\mathrm{mg} / \mathrm{dl})$} \\
\cline { 2 - 3 } \cline { 5 - 6 } & Group S & Group T & & Group S & Group T \\
\hline Preoperative & $13.2 \pm 3.7$ & $13.6 \pm 3.6$ & & $0.87 \pm 0.12$ & $0.88 \pm 0.16$ \\
POD1 & $14.7 \pm 4.2^{*}$ & $14.5 \pm 4.3$ & & $0.82 \pm 0.17$ & $0.82 \pm 0.17$ \\
POD3 & $13.4 \pm 3.8$ & $13.4 \pm 3.6$ & & $0.77 \pm 0.18$ & $0.76 \pm 0.19$
\end{tabular}

Values are mean \pm SD. Group S: inhalation anesthesia with sevoflurane, Group T: total intravenous anesthesia with propofol and remifentanil. POD1: postoperative 1 day, POD3: postoperative 3 days. $* \mathrm{P}=0.008$ compared with preoperative value. 
muscles. Therefore, ALT is a more specific test for the liver. In the present study, postoperative AST significantly increased in Group S compared to that of Group T, but the increased AST values were within the normal range. Neither group exhibited changes in postoperative ALT compared to baseline, and there were no differences in ALT between the two groups. There were no cases of AST and ALT increasing more than $100 \mathrm{IU} /$ L. Therefore, we hypothesized that postoperative hepatic dysfunction was clinically insignificant and there was no difference in hepatic function between the two groups.

Sahin et al. [5] compared the effects of inhalational anesthetics and TIVA on patients with lumbar discectomy, and found that there were no changes in postoperative liver function, and found no differences between the two groups. Their findings agree with the results of the present study. Similarly, studies performed by Yoon et al. [6] and Oh et al. [9] on laparoscopic cholecystectomy patients also agreed with our results, in that they found no differences in liver function after surgery with either inhalational anesthesia or anesthesia with propofol. However, their findings differ from those of the present study because postoperative AST and ALT increased beyond the normal range, perhaps because laparoscopic cholecystectomies are associated with relatively greater risk of liver damage due to traction and the surgery itself, more than lumbar discectomies and thyroidectomies. ALT showed no postoperative changes in the present study and in the study by Sahin et al. However, ALT increased in the studies by Yoon et al. and Oh et al. This may be due to direct surgical damage to the liver rather than the effects of sevoflurane and propofol. However, there have been reports of liver failure after anesthesia with sevoflurane in children and adults who had normal liver function $[10,11]$. There have also been reports of acute liver failure accompanied with fatty liver in patients who received propofol over long periods of time [12]. Sevoflurane and propofol generally are safe for patients with normal liver functions, but it is necessary to be aware that they can cause liver toxicity.

There is disagreement over whether sevoflurane affects kidney function. Mazze et al. [13] performed a large study and found that sevoflurane does not cause kidney insufficiency. Unlike animals, sevoflurane anesthesia does not affect kidney function in humans because human renal beta-lyase activity is lower than animal renal beta-lyase activity. Beta-lyase is an enzyme that is involved in the change of compound A into the kidney toxin cystein-S-conjugate, and it is found 8-30 times more in rats than in humans [14]. However, considering nephrotoxicity after sevoflurane anesthesia in healthy volunteers [15] and kidney insufficiency after sevoflurane anesthesia [16], further study on the effects of sevoflurane on kidney function are needed.

In the present study we used remifentanil in both groups for anesthesia maintenance. Group S used an infusion pump for continuous infusion. Group T used a TCI pump to control the effect-site concentration. Although the administration methods were different, the remifentanil doses were $1.22 \mathrm{mg}$ and $1.14 \mathrm{mg}$, respectively, so there was no difference between the two groups. Remifentanil is hydrolyzed quickly by circulating nonspecific tissue esterase. Liver and renal dysfunction found in the perioperative period does not affect opioid pharmacokinetics [17]. Thus, the remifentanil used in the present study is not considered to have affected the postoperative liver or kidney function.

The BUN levels in Group S significantly increased postoperatively. However, the BUN values were in the normal range and there was only a slight change $(1.5 \mathrm{mg} / \mathrm{dl})$. Also, a total of $40-50 \%$ of BUN is reabsorbed in the renal tubule, and the reabsorption rate increases in the hypovolemic state. If protein metabolism is not stable, it cannot represent the glomerular filtration rate [18]. Thus, it is not considered a clinically significant increase. Creatinine has a tendency to decrease postoperatively. This is considered to be due to dilution from the fluid used during surgery (approximately 1.5 L) and fluid used postoperatively (3-4 L/day). The preoperative hematocrit ( $40 \%$ ) decreased to $37 \%$ on postoperative day 1 . Therefore, considering the small amounts of perioperative blood loss (less than $50 \mathrm{cc}$ ), this finding was likely due to the fluid administered in the perioperative period. Urinary glucose and protein, neutrophil gelatinase-associated lipocalin, cystatin $\mathrm{C}$, and interleukin-18 are known to be more sensitive markers $[19,20]$. In the present study we used BUN and creatinine together to assess kidney function, so our ability to obtain good results was limited. Comparative assessments of kidney function should be made using more sensitive tests.

Liver toxicity is rare with the use of diclofenac, and the short term use of diclofenac does not cause kidney toxicity [21]. However, amoxicillin is known to cause liver and kidney failure, albeit infrequently $[22,23]$. In the present study, as there were no cases of significant liver or kidney failure, we hypothesized that the drugs (anesthetics and antibiotics) used during anesthesia had no effect on liver or kidney function.

In conclusion, inhalational anesthesia with sevoflurane and TIVA with propofol and remifentanil had little effect on postoperative liver and kidney function, and did not cause clinically significant organ insufficiency in thyroidectomy patients. However, further studies are needed in patients with preoperative liver insufficiency and in patients undergoing liver transplants or surgeries that directly affect liver function, such as hepatic resection.

\section{References}

1. Tramer M, Moore A, McQuay H. Meta-analytic comparison of 
prophylactic antiemetic efficacy for postoperative nausea and vomiting: propofol anaesthesia vs omitting nitrous oxide vs total i.v. anaesthesia with propofol. Br J Anaesth 1997; 78: 256-9.

2. O'Connor CJ, Rothenberg DM, Tuman KJ. Anesthesia and the hepatobiliary system. In: Miller's Anesthesia. 7th ed. Edited by Miller RD: Philadelphia, Elsevier Churchill Livingstone. 2010, pp 2135-49.

3. Jung BH, Chung MH, Lee SW, Won LS. Acute hepatitis after general anesthesia in a child. Korean J Anesthesiol 1995; 28: 467-71.

4. Modesti C, Sacco T, Morelli G, Bocci MG, Ciocchetti P, Vitale F, et al. Balanced anesthesia versus total intravenous anesthesia for kidney transplantation. Minerva Anestesiol 2006; 72: 627-35.

5. Sahin SH, Cinar SO, Paksoy I, Sut N, Oba S. Comparison between low flow sevoflurane anesthesia and total intravenous anesthesia during intermediate-duration surgery: effects on renal and hepatic toxicity. Hippokratia 2011; 15: 69-74.

6. Yoon JH, Cho SH, Kim CS, Ahn KR, Kwon JH, Kang KS, et al. Comparisons of propofol, enflurane, sevoflurane, and desflurane anesthesia in laparoscopic cholecystectomy on postoperative liver enzyme levels. Korean J Anesthesiol 2005; 49: 18-24.

7. Mihm FG. Endocrine surgery. In: Anesthesiologist's manual of surgical procedures. 4 th ed. Edited by Jaffe RA: Philadelphia, Lippincott Williams \& Wilkins. 2009, pp 658-9.

8. Bhattacharyya N, Fried MP. Assessment of the morbidity and complications of total thyroidectomy. Arch Otolaryngol Head Neck Surg 2002; 128: 389-92.

9. Oh SW, Koo GH, Kim SJ, Woo YC. Comparison of propofol with enflurane anesthesia in laparoscopic cholecystectomy for the change of liver function. Korean J Anesthesiol 1999; 36: 279-85.

10. Ogawa M, Doi K, Mitsufuji T, Satoh K, Takatori T. Drug induced hepatitis following sevoflurane anesthesia in a child. Masui 1991; 40: 1542-5.

11. Park JT, Lee YB, Kim JS, Ryu H, Lim HK. Acute liver injury after sevoflurane anesthesia: a case report. Korean J Anesthesiol 2009; 57: 221-4.

12. Kneiseler G, Bachmann HS, Bechmann LP, Dechene A, Heyer T, $\mathrm{Baba} \mathrm{H}$, et al. A rare case of propofol-induced acute liver failure and literature review. Case Rep Gastroenterol 2010; 4: 57-65.
13. Mazze RI, Callen CM, Galvez ST, Delgado-Herrera L, Mayer DB. The effects of sevoflurane on serum creatinine and blood urea nitrogen concentration: a retrospective, twenty-two-center, comparative evaluation of renal function in adult surgical patients. Anesth Analg 2000; 90: 683-8.

14. Iyer RA, Anders MW. Cysteine conjugate beta-lyase-dependent biotransformation of the cysteine S-conjugates of the sevoflurane degradation product compound A in human, nonhuman primate, and rat kidney cytosol and mitochondria. Anesthesiology 1996; 85: 1454-61.

15. Eger EI 2nd, Koblin DD, Bowland T, Ionescu P, Laster MJ, Fang Z, et al. Nephrotoxicity of sevoflurane versus desflurane anesthesia in volunteers. Anesth Analg 1997; 84: 160-8.

16. Tung A, Jacobsohn E. A case of nonoliguric renal failure after general anesthesia with sevoflurane and desflurane. Anesth Analg 1997; 85: 1407-9.

17. Fukuda K. Opioids. In: Miller' Anesthesia. 7th ed. Edited by Miller RD: Philadelphia, Churchill Livingstone. 2010, p 797.

18. Morgan GE Jr, Mikhail MS, Murray MJ. Clinical anesthesiology. 4th ed. New York, McGraw-Hill companies. 2006, p 743.

19. Kharasch ED, Frink EJ Jr, Zager R, Bowdle TA, Artru A, Nogami WM. Assessment of low-flow sevoflurane and isoflurane effects on renal function using sensitive markers of tubular toxicity. Anesthesiology 1997; 86: 1238-53.

20. Moore E, Bellomo R, Nichol A. Biomarkers of acute kidney injury in anesthesia, intensive care and major surgery: from the bench to clinical research to clinical practice. Minerva Anestesiol 2010; 76: 425-40.

21. Kim H, Xu M, Lin Y, Cousins MJ, Eckstein RP, Jordan V, et al. Renal dysfunction associated with the perioperative use of diclofenac. Anesth Analg 1999; 89: 999-1005.

22. Fontana RJ, Shakil AO, Greenson JK, Boyd I, Lee WM. Acute liver failure due to amoxicillin and amoxicillin/claculanate. Dig Dis Sci 2005; 50: 1785-90.

23. Fritz G, Barner C, Schindler R, Boemke W, Falke K. Amoxicillininduced acute renal failure. Nephrol Dial Transplant 2003; 18: 16602 . 